\title{
Expression of glucocorticoid and progesterone nuclear receptor genes in archival breast cancer tissue
}

\author{
Robert A Smith ${ }^{1}$, Rod A Lea ${ }^{1}$, Joanne E Curran ${ }^{1}$, Stephen R Weinstein ${ }^{2}$ and Lyn R Griffiths ${ }^{1}$
}

${ }^{1}$ Genomics Research Centre and Wesley Research Institute, Griffith University Gold Coast, Queensland, Australia

${ }^{2}$ Department of Pathology, Gold Coast Hospital, Southport, Queensland, Australia

Corresponding author: Lyn Griffiths (e-mail: L.Griffiths@mailbox.gu.edu.au)

Received: 10 June 2002 Revisions received: 10 September 2002 Accepted: 21 October 2002 Published: 7 November 2002

Breast Cancer Res 2003, 5:R9-R12 (DOI 10.1186/bcr556)

(C) 2003 Smith et al., licensee BioMed Central Ltd (Print ISSN 1465-5411; Online ISSN 1465-542X). This article is published in Open Access: verbatim copying and redistribution of this article are permitted in all media for any non-commercial purpose, provided this notice is preserved along with the article's original URL.

\begin{abstract}
Background: Previous studies in our laboratory have shown associations of specific nuclear receptor gene variants with sporadic breast cancer. In order to investigate these findings further, we conducted the present study to determine whether expression levels of the progesterone and glucocorticoid nuclear receptor genes vary in different breast cancer grades.
\end{abstract}

Methods: RNA was extracted from paraffin-embedded archival breast tumour tissue and converted into cDNA. Sample cDNA underwent PCR using labelled primers to enable quantitation of mRNA expression. Expression data were normalized against the $18 \mathrm{~S}$ ribosomal gene multiplex and analyzed using analysis of variance.

Results: Analysis of variance indicated a variable level of expression of both genes with regard to breast cancer grade $(P=0.00033$ for glucocorticoid receptor and $P=0.023$ for progesterone receptor).

Conclusion: Statistical analysis indicated that expression of the progesterone nuclear receptor is elevated in late grade breast cancer tissue.

Keywords: breast cancer, glucocorticoid receptor, nuclear receptors, progesterone receptor

\section{Introduction}

Breast cancer is the most common malignancy in women in the Western world, with an incidence approaching 1/10 individuals in the USA in 1980 [1] and 1/11 in Australia in 1991. Several genetic and environmental risk factors have already been identified, particularly for cancers with a familial basis, including mutations within the BRCA1 and $B R C A 2$ genes [2]. Other risk factors include a maternal relative with breast cancer, longer reproductive span, obesity, reproductive history and previous breast cancers [3]. Individual breast tumours are placed into one of three histological grades. These grades are representative of the degree of loss of differentiation and the acquisition of various mutations [4]. Thus, higher grade tumour cells will show fewer of the visual and functional characteristics of the cell type from which they were derived. However, cancer grade is only a rough guide to the state of any given tumour, because the biology of cancer varies wildly from one tumour to the next.
The nuclear receptor genes are an extremely large family of genes that encode similar molecules, which bind to various messenger molecules and are typically found at or near the nuclear membrane [5]. The steroid nuclear receptors are a subfamily of the nuclear receptors that bind specifically to steroid hormones. Steroid receptors consist of highly conserved DNA and ligand binding domains, and a mutable hinge region connecting the two [6]. Once the hormone for the specific receptor binds, the receptor molecule moves across the nuclear membrane and binds to a specific hormone response element, which is a specialized sequence, on the targeted genes [5]. Once bound to its target genes, the receptor complex upregulates or downregulates the transcription of those genes in a specific manner. Activated steroid receptors affect many genes that are involved in cellular metabolism and often affect the transcription of other steroid receptors [7]. The overall action of any steroid receptor pathway is rarely very simple, with many 
other signalling systems increasing, decreasing or modifying their overall effect [7].

The two nuclear receptors investigated in the present study, namely glucocorticoid receptor (GR) and progesterone receptor $(\mathrm{PgR})$, are extremely important in breast cancer physiology. PgR antagonizes many other nuclear receptors, including the oestrogen receptor (oestrogen being the most prevalent mitogenic factor in breast cancers), whereas GR increases cellular differentiation and has been known to induce apoptosis in certain cells $[6,8,9]$. The level of expression of these nuclear receptors in a cell gives an indication of how well the cell will respond to stimulation by that hormone and can be affected by many factors, including the activation of other nuclear receptors. Expression of $\mathrm{PgR}$ is known to be upregulated by an activated oestrogen receptor, whereas expression of GR is downregulated by the same receptor. Both the expression and alleles of the various nuclear receptors have been implicated in cancer development $[5,7,10,11]$. The research presented here investigates the expression levels of PgR and GR in each of the three histological grades of breast tissue, as compared with levels of those nuclear receptors in normal breast tissue.

When assaying the expression of genes in cancer it is important to remember that there is often a generalized increase in mRNA production due to heightened cellular metabolism, and certain genes that are often used to gauge alterations in expression, such as the commonly used $\beta$-actin housekeeping gene, may also be affected [12]. The gene used for the purpose in the present study, namely the $18 \mathrm{~S}$ ribosomal gene, is expressed at a basal level in all cells and is necessary for protein production. It is also used to help verify how reproducible the reverse transcription PCR is.

\section{Materials and methods Samples}

The sample population was comprised of 25 archived breast tissue sections embedded in paraffin and fixed with $10 \%$ buffered formalin on slides, with haematoxylin and eosin stained slides as a reference. All tumour samples were infiltrating ductal carcinomas. There were six samples from tumour grade 1 , seven samples each from grades 2 and 3 , and five samples of benign breast tissue as the control population. The average age of the individuals from whom the biopsies were obtained were 56.88 , $59.18,60.45$ and 55.93 years for the control group and grade 1, 2 and 3 groups, respectively. The archival breast tissue samples were obtained through collaboration with the Pathology Department of the Gold Coast Hospital, with relevant ethical approvals. For consistency, the cancer grade for each sample was determined by a single pathologist from the Gold Coast Hospital's Pathology

\section{Expression assay}

RNA was extracted from each slide by microdissection of tumour tissue, followed by dissolution of the paraffin by xylene and ethanol washes. Microdissection was performed using a scalpel under an Olympus BX60 microscope (Olympus Optical Co., Tokyo, Japan), using the haematoxylin and eosin stained slides as a guide. Microdissected tissue was then subjected to treatment with TRIzol (Invitrogen, Carlsbad, CA, USA) to extract RNA. Once the RNA was extracted, it was DNase treated to remove any DNA contamination in the sample. Finally, the samples were run through a Qiagen Rneasy minicolumn (Qiagen $\mathrm{GmbH}$, Hilden, Germany) to purify the RNA. The extracted RNA was then transcribed into cDNA, using $0.1 \mu \mathrm{l}$ AMV-RT, $0.2 \mu \mathrm{l}$ buffer, $0.5 \mu \mathrm{l}$ dNTPs and $0.5 \mu \mathrm{l}$ of oligo dTs per $20 \mu \mathrm{l}$ of RNA solution obtained. The solution was then held at $42^{\circ} \mathrm{C}$ for 80 min to facilitate transcription. Newly transcribed cDNA underwent PCR to amplify portions of the cDNA that correspond to the mRNA for the GR and PgR genes, with fluorescently tagged primers. Primer details are provided in Table 1. Fragments amplified were each approximately 100 base pairs long, allowing cDNA derived from partially degraded RNA to be fully utilized. Control for genomic DNA contamination was provided by addition of a third primer to the PCR, positioned in an intron adjacent to the amplified fragment. If genomic contamination were present, then an additional, larger, fragment would appear. To control for PCR efficiency, the GR and PgR genes were multiplexed with the ribosomal $18 S$ gene. The GR and PgR genes were quantified using an $\mathrm{ABI} 310$ Genetic Analyzer (Applied Biosystems, Foster City, CA, USA), which measured the amount of fluorescence given off by the tagged primers.

\section{Statistical analysis}

Expression data obtained for the GR and PgR genes were normalized using the expression data obtained for the $18 \mathrm{~S}$ gene, which had been multiplexed with each tumour and control sample. As mentioned above, this controls for PCR efficiency by normalizing the data. The normalized data were then analyzed using one-way analysis of variance (ANOVA) to determine whether there was a significant difference between tumour grades. However, to protect against spurious results caused by the effect of outliers, the nonparametric Kruskal-Wallis test for $\mathrm{K}$ independent groups was also employed to confirm differences between the tumour grade groups. Appropriate post hoc tests were subsequently performed to elucidate any differences found. $P<0.05$ was considered statistically significant. The software package SPSS version 10.1 was employed for all statistical analyses (SPSS Inc., Chicago, IL, USA).

\section{Results}

Expression levels for $\mathrm{GR}$ and $\mathrm{PgR}$ were determined for all archival tissue samples, and the normalized data are sum- 
Table 1

\begin{tabular}{ll}
\multicolumn{2}{l}{ Primer compositions for PCRs } \\
\hline Primer name & Sequence $\left(5^{\prime}-3^{\prime}\right)$ \\
\hline GREX2-F1* & GAGTACCTCTGGAGGACAGA \\
GREX2-R1 & GCTTCTGATCCTGCTGTTGA \\
GREX2-R2 & ATGTCCATTCTTAAGAAACAGGA \\
PREX4-F1* & ATTGATGACCAGATAACTCTCCAT \\
PREX4-R1 & CTGACGTGTTTGTAGGATCTC \\
PREX4-R2 & GTAGTTAATTTACTGCATAGAGTG \\
18S-A ${ }^{\dagger}$ & CTTAGAGGGACAAGTCGCG \\
18S-B & GGACATCTAAGGGCATCACA
\end{tabular}

${ }^{*}$ Primer labelled with TET at $5^{\prime}$; ${ }^{+}$Primer labelled with HEX at 5 '.

marised in Table 2. Statistical values are summarized in Table 3, which shows that the expression ratios for grade 3 tumours were elevated for both GR and PgR. One-way ANOVA indicated that the differences between tumour grades were significant $(P=0.00033$ and $P=0.023$ for GR and $\mathrm{PgR}$, respectively). The notable extreme ratio values seen for both genes in the grade 3 tumour group (Table 2) prompted us to analyze the data using the nonparametric Kruskal-Wallis test, which is robust against the effect of outliers. The results of that analysis also revealed a significant difference between tumour groups for the GR and PgR genes $(P=0.048$ and $P=0.001$, respectively).

In order to elucidate the source of the significant differences found in the initial analyses, post hoc testing was performed. Because parametric post hoc tests are also susceptible to severe violation of assumptions, a nonparametric method involving multiple contrasts of rank sums was conducted [13]. The results of the post hoc analysis for the PgR confirmed that expression ratios in grade 3 tumour tissues were significantly higher than in grade 1 or control tissue $(P<0.05)$. However, no significant difference was observed between grade 3 and grade 2 ratios for the PgR gene. For the GR gene, post hoc comparisons revealed no significant differences between any test groups at the 0.05 level. This is possibly due to insufficient power to detect the tumour grade effect seen here with the sample size studied.

\section{Discussion}

The GR and PgR genes are members of the steroid receptor subfamily of the nuclear receptors. The present study investigated the expression of these genes in different grades of breast cancer tissue. Results indicated that there is significant statistical evidence of a relationship between cancer grade and expression of GR and PgR within the tested population. Specifically, post hoc tests
Table 2

Normalized expression data for glucocorticoid receptor and progesterone receptor

\begin{tabular}{|c|c|c|c|}
\hline \multirow[b]{2}{*}{ Tumour grade } & \multirow[b]{2}{*}{ Sample } & \multicolumn{2}{|c|}{ Ratio } \\
\hline & & GR & $\mathrm{PgR}$ \\
\hline \multirow[t]{6}{*}{1} & 1.1 & 0.157663 & 1.704581 \\
\hline & 1.2 & 0.286386 & 0.704097 \\
\hline & 1.3 & 0.210192 & 0.677007 \\
\hline & 1.4 & 0.297708 & 0.394194 \\
\hline & 1.5 & 0.412451 & 0.851367 \\
\hline & 1.6 & 0.21291 & 1.145151 \\
\hline \multirow[t]{7}{*}{2} & 2.1 & 0.213596 & 1.334635 \\
\hline & 2.2 & 0.171545 & 1.071429 \\
\hline & 2.3 & 0.305254 & 0.836883 \\
\hline & 2.4 & 0.283253 & 1.840524 \\
\hline & 2.5 & 0.329755 & 0.811868 \\
\hline & 2.6 & 0.187681 & 0.73115 \\
\hline & 2.7 & 0.160085 & 0.729422 \\
\hline \multirow[t]{7}{*}{3} & 3.1 & 1.413502 & 1.577562 \\
\hline & 3.2 & 1.013641 & 6.979079 \\
\hline & 3.3 & 0.879098 & 9.649718 \\
\hline & 3.4 & 1.978049 & 3.449206 \\
\hline & 3.5 & 1.021454 & 34.26531 \\
\hline & 3.6 & 0.602367 & 15.52174 \\
\hline & 3.7 & 0.146503 & 1.246472 \\
\hline \multirow[t]{5}{*}{ Control } & C1 & 0.377536 & 0.441603 \\
\hline & $\mathrm{C} 2$ & 0.285381 & 0.541582 \\
\hline & C3 & 0.063817 & 0.815374 \\
\hline & $\mathrm{C} 4$ & 0.2168 & 0.64433 \\
\hline & C5 & 0.166092 & 0.383313 \\
\hline
\end{tabular}

GR, glucocorticoid receptor; PgR, progesterone receptor.

indicated that expression of the PgR gene increased in late-stage breast cancer. It is possible that the PgR may be being expressed in response to constant stimulation of oestrogen-mediated pathways, because oestrogen receptor stimulation is known to upregulate $\mathrm{PgR}$ expression [14]. This explanation is unlikely for GR because it is known to be downregulated by oestrogen receptor stimulation [15], although it is unknown whether the loss of the actual oestrogen receptor protein, as occurs in many advanced cancers, would affect GR expression.

Because both $\mathrm{GR}$ and $\mathrm{PgR}$ are oestrogen antagonists and antimitogenic agents in breast tissue, a high level of expression of these genes in an advanced cancer appears unusual. It may be that the tumour cell expresses these genes as a tumour repressing mechanism, but that another pathway in the cell is preventing translation of GR and $\mathrm{PgR}$ mRNA, maintaining a cancerous state. It is also possible that the GR and PgR genes are expressed as 
Table 3

Summary of normalized expression data for glucocorticoid receptor and progesterone receptor genes

\begin{tabular}{|c|c|c|c|c|}
\hline \multirow[b]{3}{*}{ Tumour grade } & \multicolumn{4}{|c|}{ Ratios } \\
\hline & \multicolumn{2}{|c|}{ GR } & \multicolumn{2}{|c|}{$\mathrm{PgR}$} \\
\hline & Mean & Mean rank & Mean & Mean rank \\
\hline 1 & 0.263 & 11.33 & 0.913 & 10.33 \\
\hline 2 & 0.236 & 10.29 & 1.051 & 12.86 \\
\hline 3 & 1.007 & 19.57 & 10.384 & 21.29 \\
\hline Control & 0.222 & 9.600 & 0.565 & 4.800 \\
\hline Statistic* & $F=9.644$ & $\chi^{2}=7.908$ & $F=3.900$ & $\chi^{2}=15.869$ \\
\hline$P$ value & 0.00033 & 0.048 & 0.023 & 0.001 \\
\hline
\end{tabular}

${ }^{*} \mathrm{~F}$ statistics for group means were calculated using analysis of variance and $\chi^{2}$ statistics for mean ranks were calculated using the Kruskal-Wallis test. GR, glucocorticoid receptor; PgR, progesterone receptor.

alternate isoforms of the receptors, which cannot be distinguished by the methods employed in the present study. Alternate isoforms are known for both receptors: the alternative GR, namely GR $\beta$, acts as a repressor of antioestrogenic GR (GR $\alpha$ ) activity [6]; and with the PgR alternative (i.e. $\mathrm{PgR} \beta$ ) acts as a general gene activator, in contrast to the standard $\mathrm{PgR} \alpha$ isoform, which is generally a transcription inhibitor [16]. Both of these roles appear more recognizable in advanced cancers, which are often resistant to hormonal treatments. Further studies in this area should ideally use larger sample sizes but should also attempt to investigate other nuclear receptors, as well as attempting to distinguish different receptor isoforms and identify the presence of translated receptor proteins.

\section{Conclusion}

The results of this preliminary study indicate that the expression of the GR and PgR genes is significantly related to cancer grade, especially for $\mathrm{PgR}$, increasing in late stage breast cancers. The overall significance of these results for therapeutic work is not fully clear, because the possibility of alternate isoform expression or prevention of receptor translation will have a large impact on the physiology of the cancer cell, and therefore on the appropriate treatment strategies to utilize this information.

\section{Acknowledgements}

This research was kindly supported by the Wesley Research Institute, Brisbane, Queensland, Australia.

\section{References}

1. King M-C, Roswell S, Love SM: Inherited breast and ovarian cancer: what are the risks? What are the choices? JAMA 1993, 269:1975-1980.

2. Zheng L, Li S, Boyer TG, Lee WH: Lessons learned from BRCA1 and BRCA2. Oncogene 2000, 19:6159-6175.

3. Curran JE, Weinstein SR, Griffiths LR: Polymorphisms of glutathione S-transferase genes (GSTM1, GSTP1 and GSTT1) and breast cancer susceptibility. Cancer Lett 2000, 153:113-
4. Berardo D, Allred DC, O'Connell P: Breast cancer. In: Principles of molecular medicine. Totowa, NJ: Humana Press; 1998:625632.

5. Fryer CJ, Kinyamu HK, Rogatsky I, Garabedian MJ, Archer TK: Selective activation of the glucocorticoid receptor by steroid antagonists in human breast cancer and osteosarcoma cells. J Biol Chem 2000, 275:17771-17777.

6. Keightley M-C: Steroid receptor isoforms: exception or rule? Mol Cell Endocrinol 1998, 137:1-5.

7. Dickson RB, Lippman ME. Control of human breast cancer by estrogen, growth factors, and oncogenes. Cancer Treat Res 1988, 40:119-165.

8. Lee Y-N, Lee H-Y, Lee YM, Chung H-Y, Kim S-I, Lee S-K, Park $\mathrm{BC}, \mathrm{Kim} \mathrm{K}-\mathrm{W}$ : Involvement of glucocorticoid receptor in the induction of differentiation by ginsenosides in F9 teratocarcinoma cells. J Steroid Biochem Mol Biol 1998, 67:105-111.

9. Hulkko SM and Zilliacus J: Functional interaction between the pro-apoptotic DAP3 and the glucocorticoid receptor. Biochem Biophys Res Commun 2002, 295:749-755.

10. Curran JE, Vaughan T, Lea RA, Weinstein SR, Morrison NA, Griffiths LR: Association of a vitamin $D$ receptor polymorphism with sporadic breast cancer development. Int J Cancer 1999, 83:723-726.

11. Karck U, Kommoss F: Does tamoxifen change oestrogen and progesterone receptor expression in the endometrium and breast? Eur J Cancer 2000, 36:S39-S46.

12. Selvey S, Thompson EW, Matthaei K, Lea RA, Irving MG and Griffiths LR. B-Actin: an unsuitable internal control for RT-PCR. Mol Cell Probes 2001, 15:307-311.

13. Dunn OJ. Multiple contrasts using rank sums. Technometrics 1964, 6:241-252.

14. Fazzari A, Catalano MG, Comba A, Becchis M, Raineri M, Frairia $\mathrm{R}$, Fortunati $\mathrm{N}$ : The control of progesterone receptor expression in MCF-7 breast cancer cells: effects of estradiol and sex hormone-binding globulin (SHBG). Mol Cell Endocrinol 2001, 172:31-36.

15. Krishnan AV, Swami S, Feldman D: Estradiol inhibits glucocorticoid receptor expression and induces glucocorticoid resistance in MCF-7 human breast cancer cells. J Steroid Biochem $\mathrm{Mol}$ Biol 2001, 77:29-37.

16. Pieber D, Allport VC, Bennett PR: Progesterone receptor isoform A inhibits isoform B-mediated transactivation in human amnion. Eur J Pharmaco/ 2001, 427:7-11.

\section{Correspondence}

Professor Lyn Griffiths, Genomics Research Centre and Wesley Research Institute, School of Health Science, Griffith University Gold Coast, PMB 50 Gold Coast Mail Centre QLD 9726, Australia. Phone: +61 75552 8664; fax: +61 75552 8908; e-mail: L.Griffiths@mailbox.gu.edu.au 